Higher education institutions must develop specific programs to guarantee not only the access but the success of every student, reducing the failure and dropouts rates. This must be done without compromises to the quality of the final degree awarded.

Countries must implement policies that provide access to education for socially and economically disadvantaged sectors; that establish and insure robust-quality assurance and monitoring processes; and that create a framework to encourage institutional diversity and innovative, equitable funding mechanisms. It is difficult to imagine a comprehensive solution, but each different country must try to find a good balance between funding, access, and quality in this complicated wrangle. A long-term, sustainable solution for the growth of the higher education sector is mandatory for the economic and social stability of any nation.

\section{Do Not Fall For It}

\section{DANiEL C. LeVy}

Daniel C. Levy is a State University of New York Distinguished Professor, University at Albany, New York. E-mail: dlevy@albany.edu.

Zaniness is required to try to answer a question about higher education's greatest imminent need, so I consult and paraphrase comedian Groucho Marx: "A four-year-old child could answer this question. Run out and find me a fouryear-old child, I can't make head or tail out of it." Or maybe I could escape by discrediting the question, or at least declaring it unanswerable? But those might be ungracious responses to a gracious invitation. Most of us are interested in the answers given by colleagues who have spent their professional lives studying higher education.

Does the question's reference, to what higher education needs to deal with, concern higher education's self-interests or serving others? Only the likes of university presidents and magical solution policypushers can present these interests as nearly identical. Also, how could any answer make sense across the hugely varied realities of societies, political systems, economies, levels of development, interests, and values on the one hand and of higher education structures and functions on the other? However, many colleagues may answer with research universities in mind. I could not be comfortable with a singular substantive and prescriptive action answer for all of higher education.

Higher education's biggest need is to steer clear of, or significantly modify, seductively attractive idealistic visions or policy proposals. Obviously, we want to resist insidious or meritless proposals; when they are imposed on us, we go kicking and screaming. But even the visions and proposals, which have alluring merit and should be seriously considered, come our way with vastly exaggerated claims of likely benefits. In some places, between no and inadequate allowance for the myriad costs, those that can be anticipated and those that cannot be. Compose your own list from yesteryear and today. Unfortunately, yesteryear's inflated claims remain — what increased funding of higher education will do for development, how rapid and diversified expansion of access will bring equity and productive benefits, how government money will achieve mutually held progressive aims. These claims are now joined by grand visions of how to build world-class universities and what will be reaped from quality-assurance agencies, benchmarks, massive open line courses, or increased market competition.

This is not an ivory-tower rant against outsiders. My answer holds for bold visions and proposals springing from inside academia, including from higher education studies experts. I would trust more to invisible hands-in which I have only limited trust- than to prescriptions from gurus, let alone from wise-guys outside academia, to determine what higher education needs to do.

\section{Sustaining Resources}

\section{SimON MARGinson}

Simon Marginson is professor at the Institute of Education, University College London, UK. E-mail: s.marginson@ioe.ac.uk.

The key challenge facing higher education in the next decade is mundane but central: sustaining resources. Behind that lies a deeper historic problem, relations between higher education and the nation state.

Worldwide modern higher education systems are the product of the nation-building strategies of governments. Tuition arrangements vary markedly, but overall, up till now, government has funded most of the infrastructure and most of the operating costs of better institutions in one way or another. Governments subsidize the growth of access to newly participating families and foster opportunities for social mobility through higher education. Government is also essential to funding research, a public good subject to market failure. However, matters are now changing in many countries. Research still depends on public funding, and governments want to concentrate resources there to maximize national competitiveness. But teaching can be either public or private good. 
With tertiary participation now more than 50 percent in countries with above average per capita incomes, a tipping point has been reached. Higher education has become an essential passport to full-time work and effective social status. It has become increasingly difficult for middle-class families (and in some countries, for any families) to stay outside the higher education system. There is often strong resistance to tuition increases, yet in their hearts people know they have to enroll their student-age children, even if they have to pay much of the cost themselves. The round of funding reductions in the recession of $2008 \mathrm{did}$ not trigger a decline in participation as many feared: in fact the worldwide growth of participation has never been stronger. While there are some continuing instances of demand elasticity, overall, many governments are learning that they can cut back their subsidies for higher education and force tuition rises, without paying a political price, and without reducing participation in the long run. This can only mean "we ain't seen nothing yet" and state funding will fall much further. What then happens to the public character of higher education? The public mission has always rested on the funding role of the state. Without a strong state presence is it realistic to expect institutions alone to sustain quality and social mobility?

In high participation systems the question shifts from access? to access to what? All else equal, a major shift to private costs is associated with growing stratification of quality of provision, and greater inequality of opportunity, with the upper middle class concentrated in leading institutions. Some would say we are there already, but the more important point is that as the state withdraws, the quality of mass public education collapses and it can no longer function as a springboard for mobility. Private for-profits have low completion rates and their credentials lack zing in the labor markets. In two thirds of countries, economic inequalities are increasing. If higher education worsens social stratification and blocks social empowerment, it has lost its moral foundation in the common good. It becomes an obstacle to be removed. Is this where we are heading?

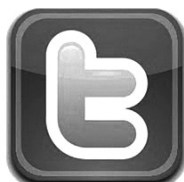

In addition to our Web site and Facebook page, we are now tweeting. We hope you will consider "following" us on Twitter!

\section{The Challenge Facing Chinese Higher Education in the Next Two Decades}

\section{Weifang Min}

Weifang Min is professor and director, Institute of Higher Education and former executive vice president, Peking University. E-mail: wfmin@pku.edu.cn.

One of the most striking aspects of higher education in the past 20 years is the rapid expansion of enrollment. In I995, the world total enrollment was 79 million with 5.2 million in China. In 20I2, it was I9 6 million and 32.6 million respectively, 2.5 times of I995 for the world, 6.2 times for China. China is the home to the world's fastest-growing higher education.

However, the state appropriation and quality inputs could not keep up with the quantitative expansion, which resulted in large class size, crowded classrooms and labs, decreased teaching equipment and library books per student, and lowered quality of teaching. Since many universities enlarged enrollment in low-cost programs-such as literature and history, instead of engineering technologies and sciences-it made the structure of graduates by expertise mismatch the labor market needs. Many graduates had difficulties to find jobs. The Chinese Ministry of Education came to realize the problems of overspeeded expansion of higher education and issued a document in 2012 , trying to stabilize the size of enrollment. However, with ever-increasing private and social demands for higher education, the expansion momentum was still forceful. In 2013, the total enrollment increased to 34.5 million. It is estimated that the total enrollment will exceed 40 million by 2020 . Chinese higher education is currently characterized as "big but not strong."

Thus, the challenge for the coming 20 years of Chinese higher education is to balance the quantitative development and qualitative improvement and to make Chinese higher education "big and strong." This will be a quite difficult task. On one hand, China has to keep a certain growing rate to meet the huge unmet demand; on the other hand, it has to adjust the higher education structure and improve the quality, to make graduates well fit in the human resource needs of the changing economic situation. Many policy measures will have to be taken. First, expansion of enrollment has to slow down to make the number of graduates be absorbed by the economy.

This issue was not seriously taken into account, before. For example, in the coming summer of 2015, China will have 7.5 million higher education graduates, while 